\title{
Cough Augmentation Techniques in the Critically Ill: A Canadian National Survey
}

\author{
Louise Rose RN PhD, Neill K Adhikari MDCM MSc, Joseph Poon, David Leasa MD FRCPC, and \\ Douglas A McKim MD FRCPC DABSM; on behalf of the CANuVENT Group
}

\begin{abstract}
BACKGROUND: Critically ill mechanically ventilated patients experience impaired airway clearance due to ineffective cough and impaired secretion mobilization. Cough augmentation techniques, including mechanical insufflation-exsufflation (MI-E), manually assisted cough, and lung volume recruitment, improve cough efficiency. Our objective was to describe use, indications, contraindications, interfaces, settings, complications, and barriers to use across Canada. METHODS: An e-mail survey was sent to nominated local survey champions in eligible Canadian units (ICUs, weaning centers, and intermediate care units) with 4 telephone/e-mail reminders. RESULTS: The survey response rate was 157 of $238(66 \%) ; 78$ of 157 units $(50 \%)$ used cough augmentation, with $50(64 \%)$ using MI-E, 53 (68\%) using manually assisted cough, and 62 (79\%) using lung volume recruitment. Secretion clearance was the most common indication (MI-E, 92\%; manually assisted cough, $88 \%$; lung volume recruitment, $76 \%$ ), although the most common units (44\%) used it $<50 \%$ of the time. Use during weaning from invasive (MI-E, 21\%; manually assisted cough, 39\%; lung volume recruitment, $3 \%$ ) and noninvasive ventilation (MI-E, $21 \%$; manually assisted cough, 33\%; lung volume recruitment, $21 \%$ ) was infrequent. The most common diagnoses were neuromuscular disease $(97 \%)$ and spinal cord injury $(83 \%)$. Pneumothorax was the most frequently identified absolute contraindication for MI-E (93\%) and lung volume recruitment $(83 \%)$; rib fracture was most frequently identified for manually assisted cough $(69 \%)$. MI-E mean inspiratory pressure was $31 \mathrm{~cm} \mathrm{H}_{2} \mathrm{O}$, and expiratory pressure was $-32 \mathrm{~cm} \mathrm{H}_{2} \mathrm{O}$. Mucus plugging requiring tracheostomy inner change was the most frequent complication for MI-E (23\%), chest pain for manually assisted cough $(36 \%)$, and hypotension for lung volume recruitment $(17 \%)$. The most commonly cited barriers were lack of expertise (70\%), knowledge (65\%), and resources $(52 \%)$. CONCLUSIONS: We found moderate adoption of cough augmentation techniques, particularly for secretion management. Lack of expertise and knowledge are potentially modifiable barriers addressed with educational interventions. Key words: cough augmentation; mechanical insufflation-exsufflation; acute respiratory failure; mechanical ventilation; intensive care. [Respir Care 2016;61(10):1360-1368. () 2016 Daedalus Enterprises]
\end{abstract}

\section{Introduction}

Critically ill patients receiving mechanical ventilation may experience impaired airway clearance as a result of

Dr Rose is affiliated with the Sunnybrook Health Sciences Centre; the Lawrence S Bloomberg Faculty of Nursing, University of Toronto; the Provincial Centre of Weaning Excellence/Prolonged Ventilation Weaning Centre, Toronto East General Hospital; Mount Sinai Hospital; the Li Ka Shing Knowledge Institute, St. Michael's Hospital; and the West Park Healthcare Centre, Toronto, Ontario, Canada. Mr Adhikari is affiliated with the Sunnybrook Health Sciences Centre, Interdivisional Department of Critical Care, University of Toronto, Toronto, Ontario, Canada. $\mathrm{Mr}$ Poon is affiliated with the Faculty of Medicine, University of Sydney, ineffective cough and impaired secretion mobilization. ${ }^{1}$ To produce an effective cough, the glottis must close; however, this action is prevented during endotracheal intubation or by glottic muscle weakness. ${ }^{2}$ Patients with respiratory muscle weakness due to ICU-acquired weakness, neuromuscular disease (NMD), spinal-cord injury (SCI), and restrictive chest wall disease are particularly at risk for

Sydney, New South Wales, Australia. Dr Leasa is affiliated with the Critical Care Western and London Health Sciences Centre and Western University, London, Ontario, Canada. Dr McKim is affiliated with the Ottawa Hospital Respiratory Rehabilitation Center, the Ottawa Hospital Sleep Centre, and the University of Ottawa, Ottawa, Ontario, Canada. 
impaired airway clearance, both during intubation and once extubated. ${ }^{2-4}$ Oversedation and lack of patient cooperation $^{2}$ due to delirium or cognitive impairment may also contribute to ineffective cough. ${ }^{5}$

Ineffective cough, impaired mucociliary transport, gravity-driven translocation of oropharyngeal pathogens, and air-flow patterns lead to secretion pooling in the lower airways, atelectasis, and ventilator-associated pneumonia, all of which contribute to weaning and extubation failure..$^{2,3,6,7}$ Although suctioning of the trachea to remove tracheobronchial and upper airway secretions is the standard of care, ${ }^{8}$ this method is ineffective for clearing peripheral airways. ${ }^{9}$ Additional techniques to stimulate and increase cough effectiveness, particularly for patients with NMD and SCI, comprise lung volume recruitment (also termed air-stacking or breath-stacking), manually assisted cough, and mechanically assisted cough using a mechanical insufflation-exsufflation (MI-E) device. Lung volume recruitment provides increased end-inspiratory volume to promote cough effectiveness. The patient serially inhales a volume of gas without exhalation until maximum insufflation capacity, ${ }^{10}$ either via the ventilator or a self-inflating resuscitation bag adapted with a one-way valve, to facilitate breath-holding. Manually assisted cough provides increased air compression in the lungs and comprises an abdominal thrust or lateral costal compression timed to glottic opening. ${ }^{11}$ During MI-E, lung insufflation targeted to $+40 \mathrm{~cm} \mathrm{H}_{2} \mathrm{O}$ is used to expand the lungs to approximately $90 \%$ of total lung capacity, followed by vacuum exsufflation to $-40 \mathrm{~cm} \mathrm{H}_{2} \mathrm{O}$, enabling lung emptying and increasing cough peak flow. ${ }^{12,13}$

Some evidence suggests that cough augmentation both during mechanical ventilation and after extubation may prevent re-intubation in critically ill ventilated patients and those considered unweanable using standard weaning methods. ${ }^{1,14}$ However, the adoption of cough augmentation techniques in the ICU is unknown. Therefore, our objective was to identify current self-reported practice

Supplementary material related to this paper is available at http:// www.rcjournal.com.

This work was supported by a grant from the Partnerships for Health Systems Improvement competition of the Canadian Institutes of Health Research. The authors have disclosed no conflicts of interest.

Dr Rose presented a version of this paper at the 2015 World Federation of Societies of Intensive and Critical Care Annual Medicine Scientific Meeting, held August 29 to September 1, 2015, in Seoul, South Korea.

Correspondence: Louise Rose RN PhD, Lawrence S Bloomberg Faculty of Nursing, University of Toronto, 155 College Street, Room, 276, Toronto, Ontario M5T IP8, Canada. E-mail: louise.rose@utoronto.ca.

DOI: $10.4187 /$ respcare. 04775

\section{QUICK LOOK}

\section{Current knowledge}

Critically ill mechanically ventilated patients experience impaired airway clearance due to ineffective cough and impaired secretion mobilization. Cough augmentation techniques, including mechanical insufflation-exsufflation, manually assisted cough, and lung volume recruitment, improve cough efficiency, although uptake of these techniques for critically ill patients is largely unknown.

\section{What this paper contributes to our knowledge}

In Canadian units managing patients requiring prolonged mechanical ventilation, there was moderate adoption of cough augmentation techniques, particularly for secretion management and in patients with neuromuscular disease and spinal-cord injury. Use to prevent intubation or re-intubation was uncommon, despite the known deleterious consequences of re-intubation and its association with impaired secretion clearance. In units that used these techniques, perception was favorable, suggesting that more consistent adoption across ICUs and other acute care units may be achievable. The most commonly cited barriers to the use of cough augmentation techniques were lack of expertise, knowledge, resources, and equipment.

in Canadian ICUs, including indications and contraindications for use of cough augmentation techniques; the type of interfaces, techniques, and MI-E settings used; complications experienced; barriers to use; and need for further evidence.

\section{Methods}

\section{Study Design and Sample}

We previously conducted a cross-sectional survey as a follow-up of our previously conducted self-reported national survey of all Canadian ICUs, high dependence units, weaning centers, and other acute care units examining care practices specific to patients requiring prolonged mechanical ventilation (response rate 215 of 238 [90\%]). ${ }^{15}$ Eligible units for the present survey comprised those units that indicated that they used lung volume recruitment, manually assisted cough, or MI-E on the initial survey. Each site was contacted via telephone to confirm or refute this use and to identify a local champion, generally a senior respiratory therapist, for survey completion. We selected senior respiratory therapists as survey champions because, in Canada, this is the professional group most commonly 
responsible for performing these procedures in the ICU. We did not attempt to contact those units that did not respond to the initial prolonged mechanical ventilation survey because we had used extensive survey recruitment methods and anticipated these units were unlikely to respond to further contact.

\section{Questionnaire Development}

Informed by an electronic database (MEDLINE, CINAHL, Embase, ISI Web of Science and Conference Proceedings, and the Cochrane Library) search (from inception to April 2014) of literature relevant to cough augmentation techniques, team members generated and iteratively refined questionnaire domains, items, and response formats. We distributed the survey to 5 international experts, representing medicine, respiratory therapy, and physiotherapy, who had previously published studies on cough augmentation for assessment of comprehensiveness, redundancy, clarity, face validity, and time to complete. ${ }^{16}$ Following further refinement based on this pilot testing, the final questionnaire comprised 6 domains: indications and contraindications, interfaces and techniques, outcomes, complications, barriers to use, and adoption and evidence. To facilitate recruitment in Quebec, a native French speaker translated the questionnaire forward into French and backwards into English.

\section{Questionnaire Administration}

We provided the online questionnaire (see the supplementary materials at http://www.rcjournal.com) via weblink (Survey Monkey) to the self-nominated survey champion from August to December 2014 (English-speaking sites) and from February to June 2015 (French-speaking sites). We sent e-mail and telephone reminders every 2 weeks for 8 weeks. Telephone contact also enabled centers to clarify questionnaire items.

\section{Ethical Considerations}

The Research Ethics Board of the University of Toronto approved the study (approval number 26199). Participation was voluntary, and consent was implied by questionnaire return.

\section{Statistical Analyses}

We used responses indicating no use of cough augmentation techniques from the original prolonged mechanical ventilation survey combined with response to this survey to determine overall use across Canada and to compare demographic data from units that did and did not use cough augmentation. We examined results using descriptive statistics, including the Sharpiro-Wilk test for normality. We summarized continuous variables using means and SD values or medians and interquartile ranges, depending on the data distribution and categorical variables using frequencies and proportions. We compared nonparametric unit demographic continuous data using the Mann-Whitney U test. We compared categorical data using chi-square or Fisher exact tests, depending on cell size and ordinal data (hospital size) using the Cochran-Armitage test. Due to missing responses, denominators vary. Analyses were conducted using SPSS 23 (IBM, Armonk, New York).

\section{Results}

Our overall survey response rate was 165 of 238 (69\%) with 157 of $238(66 \%)$ providing evaluable data (we excluded $3 \%$ of returned surveys due to $>50 \%$ missing data). As shown in Table 1, more units in the largest hospitals ( $89 \%$ of hospitals with $>600$ beds) and those with more ICU beds had adopted cough augmentation techniques compared with smaller hospitals and smaller ICUs. Of the 157 units, 78 units (50\%) used at least one cough augmentation technique; 62 of 78 (79\%) used lung volume recruitment using a manual resuscitation bag and one-way valve, 53 of $78(68 \%)$ used manually assisted cough, and 50 of 78 (64\%) units used MI-E.

\section{Indications, Patient Diagnoses, and Contraindications}

Indications for use of cough augmentation techniques are shown in Figure 1. Secretion clearance was the most common indication for all techniques (MI-E, 44 of 48 [92\%]; manually assisted cough, 43 of 49 [88\%]; lung volume recruitment, 44 of 58 [76\%]), whereas weaning from invasive (MI-E, 10 of 48 [21\%]; manually assisted cough, 19 of 49 [39\%]; lung volume recruitment, 18 of 58 [31\%]) and noninvasive (MI-E, 10 of 48 [21\%]; manually assisted cough, 16 of 49 [33\%]; lung volume recruitment 12 of 58 [21\%]) ventilation were infrequent indications. Although secretion clearance, prevention of intubation, and prevention of re-intubation were indications identified by most units, routine use was infrequent (34 units [44\%] for secretion clearance; 21 [27\%] to prevent re-intubation; 15 [19\%] to prevent intubation).

Diagnoses for which cough augmentation techniques are used are shown in Figure 2. Only 2 units (3\%) stated they would use cough augmentation techniques in all patients regardless of diagnosis. More than $50 \%$ of units stated that they did not use cough augmentation techniques for patients with COPD or acute respiratory failure. Of the 78 units using at least one cough augmentation technique, 67 reported on perceived absolute and relative contraindications. Pneumothorax was the most frequently identified 
Table 1. Site Characteristics of Units That Use and Do Not Use Cough Augmentation Techniques

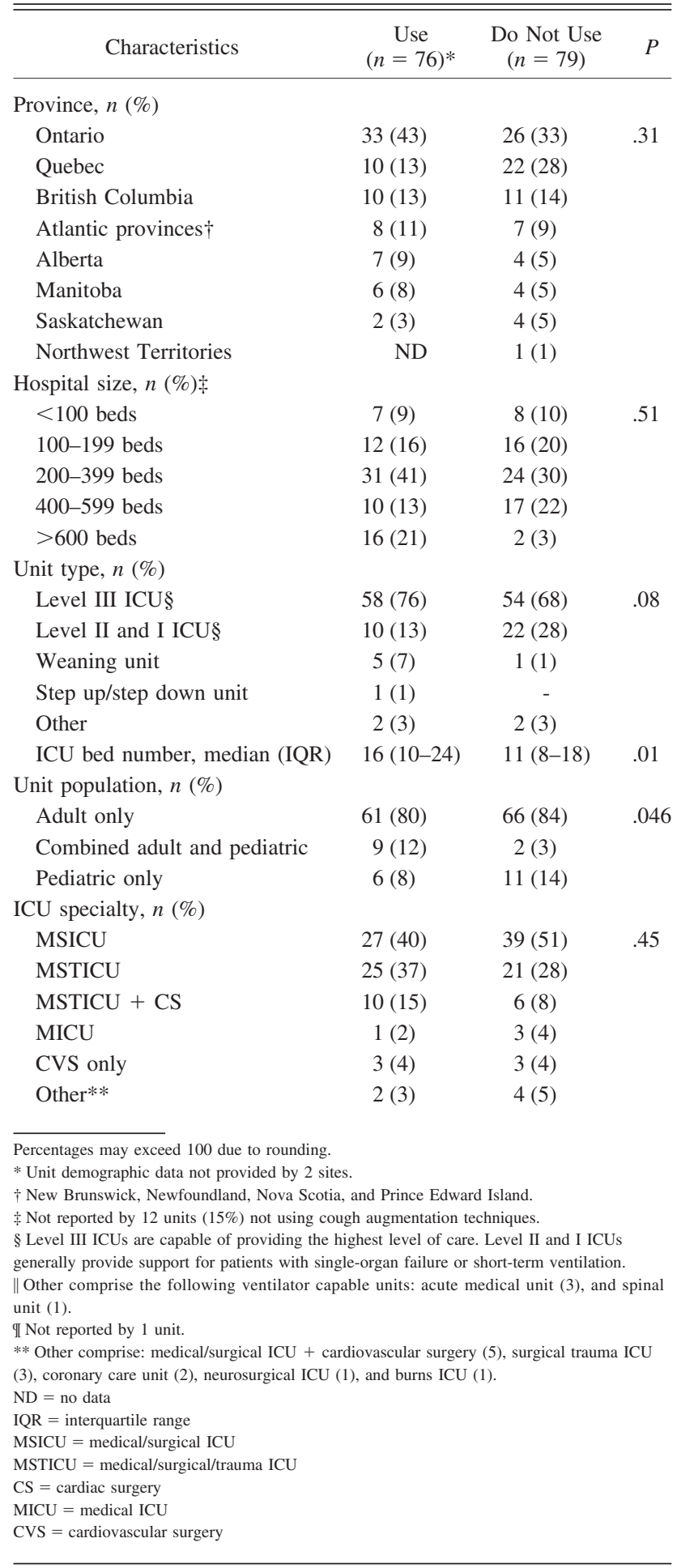

absolute contraindication for MI-E $(n=41,93 \%)$ and lung volume recruitment $(n=44,83 \%)$. Rib fracture was the most frequently identified absolute contraindication for manually assisted cough $(n=31,69 \%)$ (Table 2).

\section{Interfaces and Techniques}

Types of interfaces used are shown in Figure 3. The mean $\pm \mathrm{SD}$ inspiratory pressure used for MI-E was $31 \pm 5.8 \mathrm{~cm} \mathrm{H}_{2} \mathrm{O}$; expiratory pressure was $-32 \pm 4.8 \mathrm{~cm}$ $\mathrm{H}_{2} \mathrm{O}$. Delivery of lung volume recruitment via a tracheostomy adapter was performed by 39 of 50 units (78\%), of which 23 (59\%) delivered lung volume recruitment with the cuff deflated. Sixteen (32\%) of the 50 units used a pressure-relief valve with pressures ranging from 25 to $40 \mathrm{~cm} \mathrm{H}_{2} \mathrm{O}$, and $16(32 \%)$ used an inline pressure manometer. Of the 42 units reporting on manually assisted cough technique, 16 (38\%) used both abdominal thrust and lateral costal compression, 15 (36\%) used abdominal thrust only, and 10 (24\%) used lateral costal compression only. Of the 62 units reporting on monitoring, 15 (24\%) measured cough peak flow, and $13(21 \%)$ measured maximum insufflation capacity - vital capacity difference. Seventy units provided data on the professional groups that performed cough augmentation, with $68(97 \%)$ indicating that it was performed by respiratory therapists, $36(51 \%)$ by physiotherapists, and 17 (24\%) by registered nurses. All 3 professional groups performed cough augmentation techniques in 10 units $(14 \%)$.

\section{Complications and Barriers to Use}

Most centers reported that they perceived that complications associated with cough augmentation techniques were infrequently experienced (Table 3 ). Mucus plugging requiring tracheostomy inner cannula change was the most frequent complication perceived to be experienced during MI-E (10 of 43 units, 23\%). Chest pain was the most frequent complication for manually assisted cough (16 of $45,36 \%$ ), and hypotension was the most frequent for lung volume recruitment ( 9 of 52, 17\%). Two units reported cases of mucus plugging requiring bronchoscopy with cough augmentation. When asked what barriers existed to the use of cough augmentation techniques in their ICU, the most commonly cited barriers were lack of expertise (46 of $66,70 \%$ ), knowledge (43 of $66,65 \%$ ), resources ( 34 of $66,52 \%)$, and equipment (33 of $66,50 \%$ ) (Table 4$)$.

\section{Adoption and Evidence}

When asked whether they would encourage other clinicians to use cough augmentation techniques in acutely or critically ill patients, 47 of $60(78 \%)$ stated that they would recommend MI-E, 49 of 60 (82\%) would recommend manually assisted cough, and 47 of $63(75 \%)$ would recommend lung volume recruitment. Of the 13 participants $(31 \%)$ indicating that they would not recommend MI-E, 4 used it in their practice; 3 of 11 (27\%) saying that they would not recommend manually assisted cough used it in their practice; and 7 


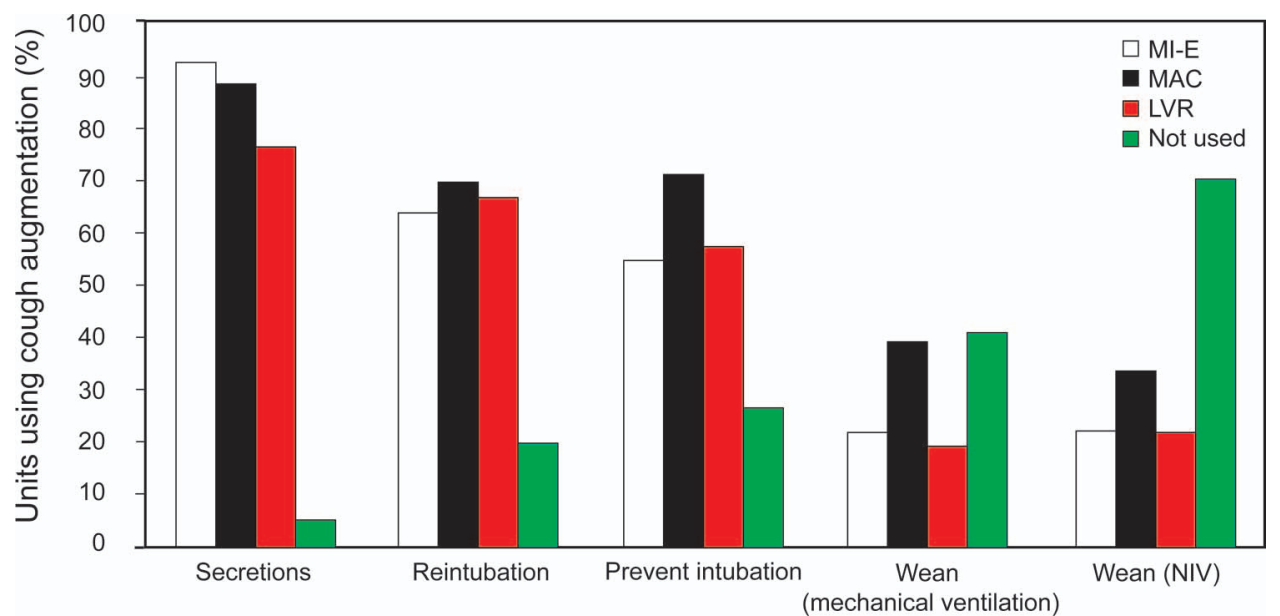

Fig. 1. Indications for cough augmentation techniques. MI-E = mechanical insufflation-exsufflation; MAC = manually assisted cough; LVR = lung volume recruitment; NIV = noninvasive ventilation.

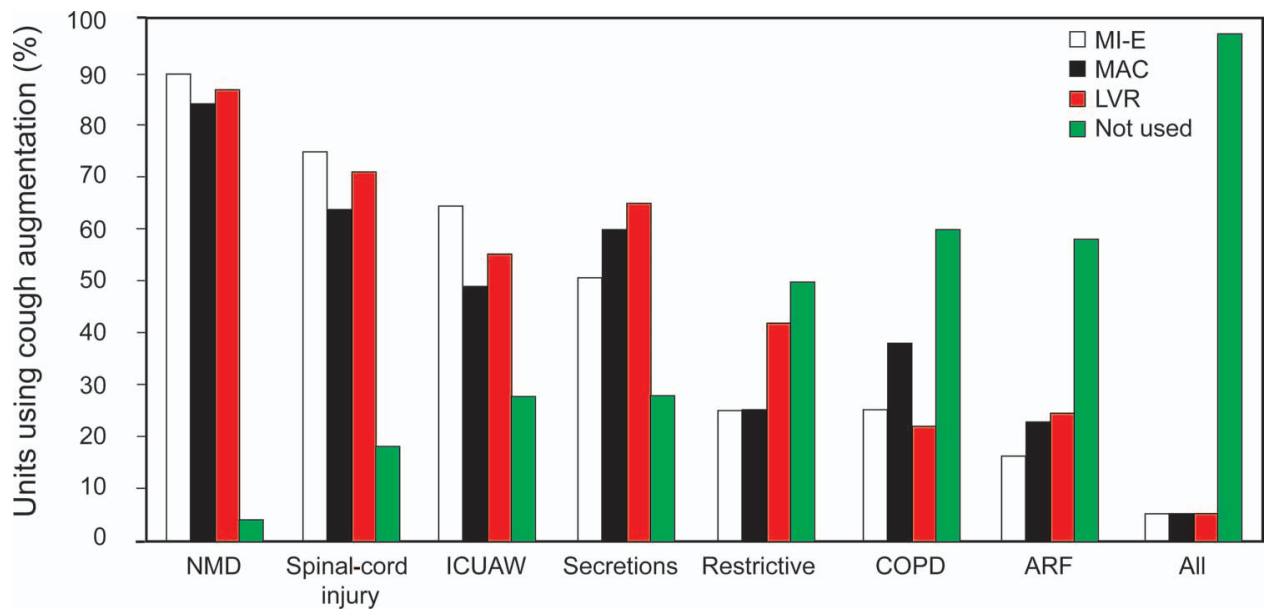

Fig. 2. Patient diagnoses. NMD = neuromuscular disease; ICUAW = ICU-acquired weakness; ARF = acute respiratory failure; Secrections = any patient with reduced lung volumes and difficulty clearing secretions, regardless of diagnosis; Restrictive = restrictive chest wall disease; MI-E = mechanical insufflation-exsufflation; MAC = manually assisted cough; LVR = lung volume recruitment.

of $16(44 \%)$ saying that they would not recommend lung volume recruitment used it in their practice. Reasons for recommending MI-E included clinical experience with the device demonstrating a "dramatic effect on the right patients"; "prevention of re-intubation until cough strength improves, particularly in the elderly, tired, or otherwise weak patient"; "more secretions are cleared, reducing the time (and need) required for suctioning"; and "patients prefer it to suctioning." Reasons for recommending manually assisted cough included "reduced need for deep invasive suctioning that usually induces more hypoxic episodes and lower airway trauma" and "easy technique to teach." Reasons for recommending lung volume recruitment included "often as effective as MI-E but cheaper" and "simple, low cost, highly effective tool to increase secretion clearance." Reasons for not recommending cough augmentation techniques included a lack of familiarity, a lack of evidence, and lack of physician support. Most participants believed that further study was required to clarify the indications and outcomes of cough augmentation techniques (MI-E, 55 of 62 [89\%]; manually assisted cough, 40 of 61 [66\%]; and lung volume recruitment, 50 of 62 [81\%]).

\section{Discussion}

Our study is the first, both across Canada and internationally, to document the use of cough augmentation techniques in Canada, specifically MI-E, manually assisted cough, and lung volume recruitment, for patients (adult and pediatric) requiring admission to an ICU or other acute care location capable of managing ventilated patients. As such, we are unable to contrast our findings with reports of cough augmentation use for the critically ill in other countries. Overall, we found that survey participants perceived 
Cough Augmentation Techniques in the Critically Ill

Table 2. Perceived Absolute and Relative Contraindications

\begin{tabular}{|c|c|c|c|c|}
\hline Contraindications & $\begin{array}{c}\text { MI-E } \\
(n=44)\end{array}$ & $\begin{array}{l}\text { Manually } \\
\text { Assisted Cough } \\
\quad(n=45)\end{array}$ & $\begin{array}{l}\text { Lung Volume } \\
\text { Recruitment } \\
\quad(n=53)\end{array}$ & $\begin{array}{l}\text { Not a } \\
\text { Contraindication } \\
(n=67)\end{array}$ \\
\hline \multicolumn{5}{|l|}{ Absolute Contraindication, n (\%) } \\
\hline Pneumothorax & $41(93)$ & $21(47)$ & $44(83)$ & $4(6)$ \\
\hline Increased ICP & $34(77)$ & $28(62)$ & $33(62)$ & $13(19)$ \\
\hline Bullous emphysema & $26(59)$ & $13(29)$ & $31(58)$ & $19(28)$ \\
\hline Hemoptysis & $21(48)$ & $15(33)$ & $20(38)$ & $32(48)$ \\
\hline Nausea and vomiting & $23(52)$ & $18(40)$ & $24(45)$ & $28(42)$ \\
\hline Impaired consciousness & $22(50)$ & $14(31)$ & $19(36)$ & $34(51)$ \\
\hline Recent thoracic or abdominal surgery & $19(43)$ & $28(62)$ & $17(32)$ & $21(31)$ \\
\hline Severe asthma & $17(39)$ & $16(36)$ & $22(42)$ & $38(57)$ \\
\hline Severe COPD & $14(32)$ & $10(22)$ & $16(30)$ & $42(63)$ \\
\hline Rib fracture & $15(34)$ & $31(69)$ & $11(21)$ & $25(37)$ \\
\hline \multicolumn{5}{|l|}{ Relative contraindication, n (\%) } \\
\hline Hemoptysis & $22(50)$ & $23(51)$ & $22(42)$ & $27(40)$ \\
\hline Impaired consciousness & $18(41)$ & $18(40)$ & $19(36)$ & $37(55)$ \\
\hline Severe asthma & $19(43)$ & $20(44)$ & $23(43)$ & $33(49)$ \\
\hline Nausea and vomiting & $15(34)$ & $21(47)$ & $19(36)$ & $35(52)$ \\
\hline Recent thoracic or abdominal surgery & $15(34)$ & $18(40)$ & $20(38)$ & $36(54)$ \\
\hline Rib fracture & $15(34)$ & $19(42)$ & $21(40)$ & $35(52)$ \\
\hline Bullous emphysema & $15(34)$ & $12(27)$ & $14(26)$ & $42(63)$ \\
\hline Severe COPD & $15(34)$ & $20(44)$ & $19(36)$ & $37(55)$ \\
\hline Increased ICP & $11(25)$ & $17(38)$ & $11(21)$ & $48(72)$ \\
\hline Pneumothorax & $9(20)$ & $15(33)$ & $11(21)$ & $47(70)$ \\
\hline \multicolumn{5}{|l|}{$\begin{array}{l}\text { * Not reported by } 11 \text { units. } \\
\text { MI-E = mechanical insufflation-exsufflation } \\
\text { ICP = intracranial pressure }\end{array}$} \\
\hline
\end{tabular}

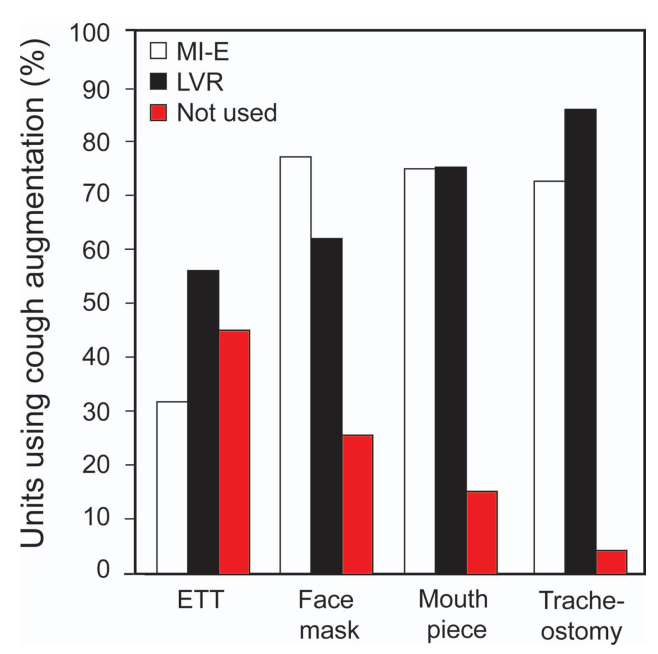

Fig. 3. Patient interfaces. ETT $=$ endotracheal tube; $M I-E=m e-$ chanical insufflation-exsufflation; LVR = lung volume recruitment.

adoption of cough augmentation techniques as modest, with lung volume recruitment the most commonly used technique. Larger units, those in the largest hospitals, and those managing a mixed adult/pediatric population were more likely to be using cough augmentation techniques.
Secretion clearance, NMD, and SCI were the most common indications. Few units used cough augmentation techniques for patients with obstructive lung disease, which probably reflects the limited and equivocal evidence in this patient population. ${ }^{17,18}$ Utilization as a tool to prevent intubation or re-intubation was uncommon, as was use across a heterogeneous ICU patient population.

Overall, study participants had a favorable view of cough augmentation techniques, citing experiential evidence of their effectiveness and recall of few complications, which reflects current evidence in the critically ill ${ }^{1,19}$ Hypotension, the most commonly recalled complication associated with lung volume recruitment, is generally transitory in nature. ${ }^{20}$ However, we recognize that this favorable perception is derived from individuals within units that use at least one cough augmentation technique and is probably biased. Irrespective of this positive perception, most participants identified the need for more evidence. To our knowledge, there are only 2 randomized controlled trials evaluating cough augmentation techniques in the critically ill patient population. Gonçalves et $\mathrm{al}^{1}$ examined the efficacy of MI-E combined with manually assisted cough for prevention of re-intubation compared with usual care. This study of a heterogeneous ICU patient population, exclud- 


\section{Cough Augmentation Techniques in the Critically Ill}

Table 3. Complications Experienced

\begin{tabular}{|c|c|c|c|c|}
\hline Complications* & $\begin{array}{c}\text { MI-E } \\
(n=43)\end{array}$ & $\begin{array}{c}\text { Manually } \\
\text { Assisted Cough } \\
(n=45)\end{array}$ & $\begin{array}{l}\text { Lung Volume } \\
\text { Recruitment } \\
\quad(n=52)\end{array}$ & $\begin{array}{l}\text { Not Experienced } \\
\quad(n=66)\end{array}$ \\
\hline Mucus plugging requiring TT inner cannula change & $10(23)$ & $8(18)$ & $8(15)$ & $44(67)$ \\
\hline Chest pain & $8(19)$ & $16(36)$ & $5(10)$ & $44(67)$ \\
\hline Bradycardia/asystole & $8(19)$ & $1(2)$ & $7(13)$ & $49(74)$ \\
\hline Hypotension & $7(16)$ & $5(11)$ & $9(17)$ & $46(70)$ \\
\hline Arrhythmias & $6(14)$ & $6(13)$ & $2(4)$ & $51(77)$ \\
\hline Mucus plugging requiring ETT change & $4(9)$ & $5(11)$ & $5(10)$ & $54(82)$ \\
\hline Pneumothorax & $4(9)$ & $2(4)$ & $6(12)$ & $53(80)$ \\
\hline Hemoptysis & $3(7)$ & $2(4)$ & $2(4)$ & $57(86)$ \\
\hline $\begin{array}{l}\text { Results are } n(\%) \\
* \text { Not reported by } 12 \text { units. } \\
\text { MI-E = mechanical insufflation-exsufflation } \\
\text { TT }=\text { tracheostomy tube } \\
\text { ETT }=\text { endotracheal tube }\end{array}$ & & & & \\
\hline
\end{tabular}

Table 4. Perceived Barriers to Use

\begin{tabular}{|c|c|c|c|c|}
\hline Barriers* & $\begin{array}{c}\text { MI-E } \\
(n=43)\end{array}$ & $\begin{array}{c}\text { Manually } \\
\text { Assisted Cough } \\
(n=45)\end{array}$ & $\begin{array}{l}\text { Lung Volume } \\
\text { Recruitment } \\
\quad(n=52)\end{array}$ & $\begin{array}{l}\text { Not a Barrier } \\
\quad(n=66)\end{array}$ \\
\hline Inadequate resources & $28(65)$ & $23(51)$ & $20(38)$ & $32(48)$ \\
\hline Lack of equipment & $27(63)$ & $3(7)$ & $5(10)$ & $33(50)$ \\
\hline Lack of knowledge & $26(60)$ & $20(44)$ & $22(42)$ & $23(35)$ \\
\hline Lack of expertise & $25(58)$ & $27(60)$ & $22(42)$ & $20(30)$ \\
\hline Insufficient evidence & $10(23)$ & $7(16)$ & $7(13)$ & $44(67)$ \\
\hline Lack of support from medical team & $14(33)$ & $12(27)$ & $14(27)$ & $40(61)$ \\
\hline Perceived risk & $8(19)$ & $7(16)$ & $10(19)$ & $43(65)$ \\
\hline Patient adherence & $15(35)$ & $12(27)$ & $19(37)$ & $36(55)$ \\
\hline \multicolumn{5}{|l|}{$\begin{array}{l}\text { Results are } n(\%) \\
* \text { Not reported by } 12 \text { units. } \\
\text { MI-E = mechanical insufflation-exsufflation }\end{array}$} \\
\hline
\end{tabular}

ing those with NMD, found a significantly lower reintubation rate ( $17 \%$ vs $48 \%$ ) in the study group compared with control. ${ }^{1}$ A second small trial $(N=20)$ examined the effect of lung volume recruitment and manually assisted cough, compared with usual chest physiotherapy, on atelectasis. $^{21}$ This study was terminated early for failure to recruit; it reported no respiratory or cardiac complications associated with the procedure. In the largest non-randomized study, Bach et al ${ }^{14}$ studied 157 subjects with NMD and weakness who were considered unweanable (multiple failed spontaneous breathing trials). Using MI-E and manually assisted cough before and after extubation to noninvasive ventilation, they found $100 \%$ extubation success for subjects with assisted cough peak flow $\geq 160 \mathrm{~L} / \mathrm{min}$ and $80 \%$ success of extubations in subjects with cough peak flow $\leq 160 \mathrm{~L} / \mathrm{min}$. These results suggest that cough augmentation techniques should be considered for patients with neuromuscular weakness. However, the highly select nature of this study population and its conduct in 2 centers with substantial experience with these techniques means that study findings are unlikely to be highly generalizable to a heterogeneous ICU population in other centers. Using a historical control group receiving standard medical treatment, Vianello et al $^{22}$ demonstrated that extubation to noninvasive ventilation used in combination with manually assisted cough and MI-E decreased the need for re-intubation and tracheostomy in subjects with neuromuscular disease.

Considering re-intubation rates of up to $29 \%, 23$ the low frequency of complications associated with the procedure, ${ }^{24}$ the negative implications of re-intubation on mortality and stay in observational studies, ${ }^{23,25}$ and the association of ineffective cough with extubation failure, ${ }^{26}$ additional studies of cough augmentation techniques are warranted. Further studies should examine the efficacy of cough augmentation techniques in the critically ill to establish the most beneficial technique(s), the subgroup(s) of critically 
ill patients most likely to benefit, and the effectiveness of these techniques on patient outcomes compared with standard suctioning and physiotherapy practices.

Although clinical practice guidelines recommend cough augmentation techniques for use in non-critically ill patients, evidence in this patient population also is limited. Guidelines for physiotherapy in medically stable adults, ${ }^{27}$ home mechanical ventilation, ${ }^{28}$ and children with neuromuscular weakness ${ }^{29,30}$ all provide strong recommendations for cough augmentation techniques for patients with poor cough efficiency to prevent atelectasis, pneumonia, and respiratory failure. All recommendations are based on low quality or very low quality evidence. A 2013 Cochrane systematic review of MI-E for patients with neuromuscular disorders identified only 5 trials of 105 participants, with none reporting on mortality or long-term outcomes.

In our study, the most commonly cited barriers to use of cough augmentation techniques in units that used these techniques were lack of expertise, knowledge, resources, and equipment. Barriers and facilitators are determinants of practice that have the potential to influence adoption of clinical practices and technology. ${ }^{31}$ To enable change in clinical practice, it is important to target those barriers that are potentially modifiable through education and quality improvement strategies. ${ }^{32}$ As such, lack of expertise and knowledge about cough augmentation techniques may be readily addressed by educational interventions. Provision of equipment and the resources to deliver cough augmentation techniques requires a financial commitment, particularly for MI-E, which may not be easy to secure until further evidence of effectiveness is available.

This study had several strengths and limitations. Study strengths include rigorous survey development and a response rate suggesting that results are representative of Canadian practice. As with any self-report survey, our study is limited in that it describes perceived as opposed to actual practice. This may result in inaccuracies due to inadequate knowledge or social desirability bias. Additionally, due to our objective of describing current selfreported practice for lung volume recruitment, manually assisted cough, and MI-E and to limit survey length to optimize response rates and decrease missing data, we did not investigate other procedures to facilitate sputum removal, including suction techniques and manual lung hyperinflation.

\section{Conclusions}

We found moderate adoption of cough augmentation techniques, particularly for secretion management and in patients with NMD and SCI. However, few units used cough augmentation routinely. Use to prevent intubation or re-intubation was uncommon, despite the known dele- terious consequences of re-intubation and its association with impaired secretion clearance. Overall, in units that used these techniques, perception was favorable, which suggests that more consistent adoption across ICUs and other acute care units may be achievable. Additionally, lack of expertise and knowledge about cough augmentation are potentially modifiable barriers that can be readily addressed with educational interventions. However, to convince decision makers to adopt these techniques, more evidence regarding the efficacy of cough augmentation techniques is required.

On behalf of the CANuVENT Group:

Reshma Amin, MD, The Hospital for Sick Children

Monica Avendano, MD, West Park Healthcare Centre

Sandra Dial, MD, Montreal Chest Institute

Eddy Fan, MD, Toronto General Hospital

Ian Fraser, MD, Michael Garron Hospital

Robert Fowler, MD, Sunnybrook Health Sciences Centre

Roger Goldstein, MD, West Park Healthcare Centre

Sherri Katz, MD, Children's Hospital of Eastern Ontario

Judy King, PhD, University of Ottawa

David Leasa, MD, London Health Sciences Centre

Cathy Mawdsley, RN, MSc, London Health Sciences Centre

Douglas McKim, MD, Ottawa Hospital

Mika Nonoyama, PhD, University of Ontario Institute of Technology

Jeremy Road, MD, Provincial Respiratory Outreach Program, Vancouver Coastal Health

Louise Rose, $\mathrm{PhD}$, University of Toronto

Gordon Rubenfeld, MD, Sunnybrook Health Sciences Centre

\section{REFERENCES}

1. Gonçalves MR, Honrado T, Winck JC, Paiva JA. Effects of mechanical insufflation-exsufflation in preventing respiratory failure after extubation: a randomized controlled trial. Crit Care 2012;16(2):R48.

2. Smina M, Salam A, Khamiees M, Gada P, Amoateng-Adjepong Y, Manthous CA. Cough peak flows and extubation outcomes. Chest 2003;124(1):262-268.

3. Salam A, Tilluckdharry L, Amoateng-Adjepong Y, Manthous CA. Neurologic status, cough, secretions and extubation outcomes. Intensive Care Med 2004;30(7):1334-1339.

4. Bach JR, Saporito LR. Criteria for extubation and tracheostomy tube removal for patients with ventilatory failure. A different approach to weaning. Chest 1996;110(6):1566-1571.

5. Pandharipande PP, Girard TD, Jackson JC, Morandi A, Thompson JL, Pun BT, et al. Long-term cognitive impairment after critical illness. N Engl J Med 2013;369(14):1306-1316.

6. Konrad F, Schreiber T, Brecht-Kraus D, Georgieff M. Mucociliary transport in ICU patients. Chest 1994;105(1):237-241.

7. Li Bassi G, Marti JD, Saucedo L, Rigol M, Roca I, Cabanas M, et al. Gravity predominates over ventilatory pattern in the prevention of ventilator-associated pneumonia. Crit Care Med 2014;42(9):e620-e627. 


\section{Cough Augmentation Techniques in the Critically Ill}

8. Branson RD. Secretion management in the mechanically ventilated patient. Respir Care 2007;52(10):1328-1342; discussion 1342-1347.

9. Nakagawa NK, Franchini ML, Driusso P, de Oliveira LR, Saldiva $\mathrm{PH}$, Lorenzi-Filho G. Mucociliary clearance is impaired in acutely ill patients. Chest 2005;128(4):2772-2777.

10. Toussaint M, Boitano LJ, Gathot V, Steens M, Soudon P. Limits of effective cough-augmentation techniques in patients with neuromuscular disease. Respir Care 2009;54(3):359-366.

11. Bach JR. Noninvasive respiratory management of high level spinal cord injury. J Spinal Cord Med 2012;35(2):72-80.

12. Gomez-Merino E, Bach JR. Duchenne muscular dystrophy: prolongation of life by noninvasive ventilation and mechanically assisted coughing. Am J Phys Med Rehabil 2002;81(6):411-415.

13. Bach JR, Barrow SE, Goncalves M. A historical perspective on expiratory muscle aids and their impact on home care. Am J Phys Med Rehabil 2013;92(10):930-941.

14. Bach JR, Gonçalves MR, Hamdani I, Winck JC. Extubation of patients with neuromuscular weakness: a new management paradigm. Chest 2010;137(5):1033-1039.

15. Rose L, Fowler RA, Fan E, Fraser I, Leasa D, Mawdsley C, et al. Prolonged mechanical ventilation in Canadian intensive care units: a national survey. J Crit Care 2015;30(1):25-31.

16. Burns KE, Duffett M, Kho ME, Meade MO, Adhikari NK, Sinuff T, et al. A guide for the design and conduct of self-administered surveys of clinicians. CMAJ 2008;179(3):245-252.

17. Winck JC, Gonçalves MR, Lourenço C, Viana P, Almeida J, Bach JR. Effects of mechanical insufflation-exsufflation on respiratory parameters for patients with chronic airway secretion encumbrance. Chest 2004;126(3):774-780.

18. Sivasothy P, Brown L, Smith IE, Shneerson JM. Effect of manually assisted cough and mechanical insufflation on cough flow of normal subjects, patents with chronic obstructive pulmonary disease (COPD), and patients with respiratory muscle weakeness. Thorax 2001;56(6):438-444.

19. Avena Kde M, Duarte AC, Cravo SL, Sologuren MJ, Gastaldi AC. Effects of manually assisted coughing on respiratory mechanics in patients requiring full ventilatory support. J Bras Pneumol 2008; 34(6):380-386.

20. Molgat-Seon Y, Hannan L, Fougere R, Bahaudden H, McKim DA, Sheel AW, et al. Acute changes in respiratory mechanics following lung volume recruitment in individuals with Duchenne Muscular Dystrophy. Am J Respir Crit Care Med 2014;189:A3552.
21. Crowe J, Rajczak J, Elms B. Safety and effectiveness of breath stacking in management of persons with acute atelectasis. Physiother Can 2006;58(4):306-314.

22. Vianello A, Arcaro G, Braccioni F, Gallan F, Marchi MR, Chizio S, et al. Prevention of extubation failure in high-risk patients with neuromuscular disease. J Crit Care 2011;26(5):517-524.

23. Frutos-Vivar F, Esteban A, Apezteguia C, González M, Arabi Y, Restrepo MI, et al. Outcome of reintubated patients after scheduled extubation. J Crit Care 2011;26(5):502-509.

24. Elmer J, Lee S, Rittenberger JC, Dargin J, Winger D, Emlet L. Reintubation in critically ill patients: procedural complications and implications for care. Crit Care 2015;19:12.

25. Menon N, Joffe AM, Deem S, Yanez ND, Grabinsky A, Dagal AH, et al. Occurrence and complications of tracheal reintubation in critically ill adults. Respir Care 2012;57(10):1555-1563.

26. Thille AW, Boissier F, Ben Ghezala H, Razazi K, Mekontso-Dessap A, Brun-Buisson C. Risk factors for and prediction by caregivers of extubation failure in ICU patients: a prospective study. Crit Care Med 2015;43(3):613-620.

27. Bott J, Blumenthal S, Buxton M, Ellum S, Falconer C, Garrod R, et al. Guidelines for the physiotherapy management of the adult, medical, spontaneously breathing patient. Thorax 2009;64(Suppl 1):i1-i52

28. McKim DA, Road J, Avendano M, Abdool S, Cote F, Duguid N, et al. Home mechanical ventilation: a Canadian Thoracic Society clinical practice guideline. Can Respir J 2011;18(4):197-215.

29. Hull J, Aniapravan R, Chan E, Chatwin M, Forton J, Gallagher J, et al. British Thoracic Society guideline for respiratory management of children with neuromuscular weakness. Thorax 2012;67(Suppl 1):i1-i40

30. Finder JD, Birnkrant D, Carl J, Farber HJ, Gozal D, Iannaccone ST, et al. Respiratory care of the patient with Duchenne muscular dystrophy: ATS consensus statement. Am J Respir Crit Care Med 2004; 170(4):456-465.

31. Baker R, Camosso-Stefinovic J, Gillies C, Shaw EJ, Cheater F, Flottorp $\mathrm{S}$, et al. Tailored interventions to address determinants of practice. Cochrane Database Syst Rev 2015;(4):CD005470.

32. Grol R, Wensing M. What drives change? Barriers to and incentives for achieving evidence-based practice. Med J Aust 2004;180(6 Suppl): S57-S60. 